\title{
Metaphor, Religion, and Gender: \\ A Case Study of Metaphor Analysis in Islamic Motivational Speech Corpus
}

\author{
Norasyikin Abdul Malik ${ }^{1 *}$ \& Faizah Mohamad ${ }^{2}$ \\ ${ }^{1}$ Academy of Language Studies \\ Universiti Teknologi MARA Cawangan Perak \\ 32610 Seri Iskandar, Perak \\ noras967@uitm.edu.my \\ *corresponding author \\ ${ }^{2}$ Academy of Language Studies \\ Universiti Teknologi MARA \\ 40450 Shah Alam, Selangor \\ fareema@uitm.edu.my
}

\begin{abstract}
Metaphor plays a vital role in human communication and its presence is evident in various discourses across genres. Nevertheless, there is a scarcity in the study of metaphors used among different genders especially in religious discourse. Thus, the current study aims to examine metaphor use in religious motivational speeches between two (male and female) speakers. A corpus-based approach, that involved analysis of keywords, collocation, and concordance, was selected in identifying linguistic metaphors while conceptual mapping (Lakoff \& Johnson, 1980) was chosen to identify conceptual metaphors in both corpora. The main data consist of four speeches of Yasmin Mogahed (YM Corpus) and four speeches of Nouman Ali Khan's speeches (NAK Corpus) retrieved from their YouTube Channels. \#LancsBox 5.0 was chosen as the tool in analysing the language patterns. From the findings, it can be concluded Yasmin used a higher frequency of metaphors compared to Nouman. This is evident from the results in the collocation analysis in YM corpus that showed seven collocates ('SWT', 'heart', 'foundation', 'healthy', 'fear', 'solid', and 'fill') were predetermined to have signals of metaphorical expressions as compared to NAK corpus that only has four collocates ('evil', 'syirik', 'religion', and 'faith') with signals of metaphorical expressions. It is also apparent that the variety of metaphors used by Yasmin is more diverse (BUILDING, HUMAN/LIVING ORGANISM, TREE, and CONTAINER metaphors) as compared to Nouman that only uses COMPUTER FILE and CONTAINER metaphors. Yasmin's choice of metaphors seems to be heavily influenced with the common metaphors used in the Qur'an, while Nouman's lack choice of metaphors indicate his preference in explaining religious concepts through literal explanation instead of metaphorical one. Future studies are recommended to have a bigger sample to better differentiate the metaphor usage between genders. It is also imperative for future research to further examine the implications of different choice of metaphors on the construction of meaning in the Islamic motivational religious corpus between different genders.
\end{abstract}

Keywords: Corpus Linguistics, Metaphor Analysis, Metaphor between Genders, Religious Metaphors, Islamic Motivational Speeches

\section{Introduction}

Metaphor has been used in various genres of both written and spoken discourses. It is also one of the common rhetorical strategies used by authors or orators in their writings or speeches (Semino \& Steen, 2008). The predominant study of metaphor used to be on literary works, translated text, political speeches, and newspaper articles. Nevertheless, the scope of the study has been extended to various genres such as politics (e.g. Lenard \& Ćosić, 2017; Stojan \& Mijić, 2019), education (e.g. Cortazzi \& Jin, 1999; Kamberi, 
2014; Dincel, 2019; Boers, 2000; Cameron 2003), advertisements (e.g. Jeong, 2008; Van Mulken, Van Hooft, \& Nederstigt, 2014), and even religion (e.g. Charteris-Black, 2004; Maula, 2016; Mohamed, 2014; Noureldin, \& Kaigama, 2015; Shokr, 2006; Suhadi, 2011). Nevertheless, there is still scarcity of metaphor study in spoken religious discourse as much attention has been given on the metaphor use in the Holy scriptures like the Bible and the Quran (e.g. Charteris-Black, 2004; Abdulmoneim, 2006; Mohamed, 2014) as well as prophetic traditions (E.g. El-Shariff, 2011). Few studies of metaphor that were done on spoken religious spoken discourse mainly highlight persuasive discourse or rhetorical devices of the preaches of speakers (Alkhodari \& Habil, 2019; Ismail, 2017; Ladika, 2018; Mustapha \& Abdul Razak, 2019) but not specifically how metaphor was used. In addition, there was also a scarcity of how men and women used metaphors in the past literature (Koller \& Semino, 2009). As much attention has been given to how male and female are represented in the media (see Hellinger, 2006; Hercberg, 2007), the current study addresses how metaphor is used in spoken religious discourse, namely Islamic motivational discourse, between male and female speakers.

The traditional conceptualization of metaphor is a form of comparison that equates two things that may at first seem completely dissimilar and is often an abstract idea and a concrete image. In the past, metaphor was commonly used in literary discourses especially in poetry and it was considered as a significant element in poetry writing. Yet, Lakoff and Johnson (1980, p.6) claimed that "metaphors as linguistic expressions are possible precisely because there are metaphors in a person's conceptual system". Due to this theory, metaphors offer an avenue of how language can be structured and on the means in which people think and learn (Krennmyar, 2011). The theoretical background relies on the notion of metaphor as both a conceptual and a linguistic phenomenon (Lakoff \& Johnson, 1980), which is combined with a social constructivist view on gender and language.

\section{Conceptual Metaphor Theory (CMT)}

Conceptual Metaphor Theory (CMT) (Lakoff \& Johnson, 1980) suggests metaphor as a way in explaining abstract ideas by using a concrete entity. It is also considered as both cognitive and linguistic level of expression. At the linguistic level, metaphor may be expressed as we have reached the crossroads, we have come to the end of the road, and there is no turning back in our relationship. These metaphoric expressions are called linguistic metaphors. Using conceptual mapping proposed in CMT, these linguistic metaphors are mapped together to identify the conceptual metaphor LOVE IS A JOURNEY. This conceptual mapping relates to the cognitive level of metaphor. Figure 2.1 displays a hypothetical conceptual mapping based on LOVE IS A JOURNEY metaphor. 


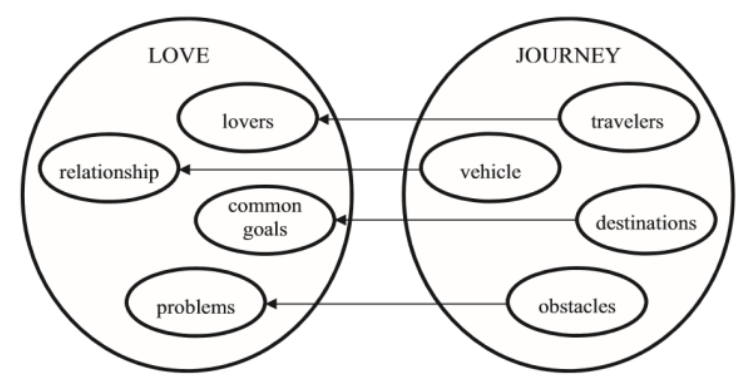

Figure 3.3: Hypothetical conceptual mapping (Holyoak \& Stamenkovi'c, 2018).

Generally, metaphor is divided into three main categories: (i) structural; (ii) orientational; and (iii) ontological (Lakoff \& Johnson, 1980). Table 2.1 displays the description of the metaphor categories.

Table 2.1: Categories of metaphors (Lakoff \& Johnson, 1980; 2003)

\begin{tabular}{|c|c|c|c|}
\hline No. & Categories & Description & Examples \\
\hline 1. & Orientational & $\begin{array}{l}\text { It is based on spatial relations like up and } \\
\text { down. }\end{array}$ & "You need to cheer up" (GOOD IS UP) \\
\hline 2. & Structural & $\begin{array}{l}\text { It uses a highly abstract concept in structur- } \\
\text { ing a concrete concept. }\end{array}$ & LOVE IS A JOURNEY \\
\hline 3. & Ontological & $\begin{array}{l}\text { It is divided into three categories: } \\
\text { a) Entity - identifies abstract experi- } \\
\text { ences as entities or substances. } \\
\text { b) Container - refers to abstract expe- } \\
\text { rience as containers. } \\
\text { c) Personification - represents an ab- } \\
\text { stract experience as an entity or a } \\
\text { person. }\end{array}$ & $\begin{array}{l}\text { My fear of insects is driving my } \\
\text { wife crazy (FEAR IS AN ENTITY) } \\
\text { The feeling is boiling up in the body. } \\
\text { (EMOTION IS A CONTAINER) } \\
\text { Inflation is lowering our standard } \\
\text { of living (INFLATION IS AN } \\
\text { ENTITY/PERSON) }\end{array}$ \\
\hline
\end{tabular}

\section{Corpus Approach in the Study of Metaphor}

Corpus-based or corpus-driven method is increasingly implemented in the study of conceptual metaphors. Since the renowned Conceptual Metaphor Theory (CMT) by Lakoff and Johnson (1980) only involves manual identification of metaphorical expressions, many researchers have come out with more systematic approach that make use of empirical data in identifying traces of metaphorical expressions used in a discourse. Corpus approach has been integrated in the used-to-be manual approach in identifying metaphors. Using frequency lists, collocational analysis, and in-depth analysis of the concordance lines, the metaphor identification can now be carried out systematically. For example, Adnan (2014) combined a corpus-based method and CMT in analysing metaphors between the original and simplified version of a literary work using an online corpus tool Wmatrix with other linguistic analysis tools like USAS tagger and POS tagger 
CLAWS. Another example is a study done by Semino, Demjén, Demmen, Koller, Payne, Hardie, and Rayson (2015) who also used Wmatrix in analysing VIOLENCE and JOURNEY metaphors used by cancer patients and health professionals when writing online. Meanwhile, Ahrens and Jiang (2020) analysed collocational patterns in Sketch Engine and other software - SUMO (Suggested Upper Merged Ontology), WordNet, and an online dictionary to study the BUILDING metaphor in political discourse. With regards to the aim of the current study, this statistical evidence in the keyword lists is paramount in allowing a metaphor analyst to make a strong claim of a dominant use of metaphor in a discourse (Semino, 2017). As the orthodox approach of the early detection of metaphor is through close-reading and manual detection, this statistic result reduces the tendency for the discourse analysts to interfere with the result of a study (Partington, 2007). To bridge the gap in metaphor studies, this case study therefore employed a corpus-based approach to identify the metaphorical expressions/linguistic metaphors used in newly built corpora, collections of Islamic motivational speeches by two prominent speakers of different genders (this is further elaborated in methodology section).

\section{Metaphors in Religious Discourse}

Metaphor plays a vital role in human communication as Lakoff (1993) deems that it is a mode of thought and not just a literary element. Nonetheless, despite its ubiquity in various discourses across genres, there is still only a handful of studies done on the use of metaphor in spoken religious discourse especially with Islamic content compared to spoken political discourse. This can be seen as the past studies reflected the focus of metaphor study in Islamic religious discourse was mainly done on holy scriptures like the Qur'an (see Abdulmoneim, 2006; Charteris-Black, 2004; Mohamed, 2014, Nurbayan, 2019) and prophetic traditions (El-Shariff, 2011). For example, Charteris-Black (2004) who is well-known with his Critical Metaphor Analysis (CMA) has done extensive research on the use of metaphors in religious discourses, namely the Old Testament, the New Testament, and the Qur'an. In the analysis done on metaphors in the Qur'an, he found that LIGHT metaphor is widely employed in religious text. It is also evident that the LIGHT metaphor in the Qur'an reveals the conceptual metaphor SPIRITUAL KNOWLEDGE IS LIGHT and SPIRITUAL IGNORANCE IS DARKNESS (Charteris-Black, 2004). Another example is from Mohamed's (2014) study on metaphors in the Qur'an that focused on the representations of natural events in the Qur'an. He identified five categories of natural phenomena metaphors: RAIN, MOUNTAIN, WIND, LIGHT, and DARKNESS. Meanwhile for spoken discourse, the focus was more on persuasive discourse or rhetorical devices of the preachers of speakers (Alkhodari \& Habil, 2019). Through the current study, a corpus on metaphors in Islamic teaching can be generated and added. In addition, metaphor analysis in terms of conceptual metaphors may provide a better understanding of religious reasoning (Shokr, 2006), which in turns help either the believers or the non- 
believers to deepen their understanding of Islamic concepts and values. Lastly, there is a need for a better understanding of the potential of metaphors in teaching religion and other types of knowledge and the finding can add more evidence on its existence and potential in teaching complex ideas.

\section{Metaphor Usage between Gender}

In the contemporary study of gender and language, the social constructivist view of gendered language behavior is usually referred to (Koller \& Semino, 2009). In this theory, speakers of different genders employ language to present themselves as either masculine or feminine. These preferences are not due to their biology nor upbringing, but it is fundamentally motivated by contextual factors. In other words, a certain use of language, which includes metaphor, can be explained based on the how the speakers exhibit a certain linguistic behaviour that indicates either masculine or feminine, regardless their biological sex. Thus, the current study relies on this belief in making sense of the metaphors used by both selected speakers. Metaphor is usually used in a discourse whether to persuade or manipulate the audience, receiver, or listener (Koller \& Semino, 2009), but it also has a role in crafting gender identities which have been examined and analysed across various cultures and discourses. They are investigated within three dimensions:

a) Gendered metaphors used to represent power inequality (Koller 2004; Velasco Sacristan, 2005)

b) Metaphors used in representing to either men or women (Koller 2004)

c) Metaphors used by either men and women (Koller \& Semino, 2009)

Since throughout the years, attention has been given to how male and female are represented in the media (e.g. Hellinger, 2006; Hercberg, 2007), hence, the current study addresses the third dimension due to the scarcity of how men and women use metaphors in the past literature (Koller \& Semino, 2009).

\section{Research Questions}

1) Do Yasmin Mogahed and Nouman Ali Khan employ metaphors with similar frequency?

2) Are there similarities or differences in the metaphors used by Yasmin Mogahed and Nouman Ali Khan?

\section{Methodology}

The nature of this research is both quantitative and qualitative. The type of discourse is oral specifically Islamic motivational speeches published on YouTube. Since the case study aims to investigate the metaphor usage between genders, two Islamic motivational speakers of different genders were chosen, namely Yasmin Mogahed and Nouman Ali Khan. Since the nature of the discourse is oral, the number of speeches analysed in this study is limited due to the constraint in converting the speech to textual data. Thus, 
the sample is amongst the eight randomly selected speeches of both speakers (four speeches per speaker) in the recent years (2019-2020). The tools involved in analysing the newly built corpora are \#Lancsbox 7.0 and Oxford Learner's Dictionary. The former is a corpus tool in analysing the language patterns through analysis of keyword list, collocates, and concordance lines. Meanwhile, the latter is used to determine the existence of semantic tension in detecting words or phrases indicating linguistic metaphors. The evidence of semantic tension can be identified when an abstract experience or entity, like 'cancer experience' is described with a physical experience/entity, like 'battle'. As 'battle' is defined as 'a fight between armies, ships or planes, especially during a war; a violent fight between groups of people" (Oxford Learner's Dictionary, 2020), semantically it does not literally link to 'cancer experience', which means 'battle' is metaphorically used in this context. Hence, the linguistic metaphors in the corpora can be detected and certified systematically.

\section{Samples}

The corpora were built from the speeches of two influential Islamic speakers from different genders: Nouman Ali Khan and Yasmin Mogahed. These speakers were chosen mainly because they have ingrained similar influence as Islamic motivational speakers in Malaysia, as well as several other factors:

a) Deliver speeches in English language.

b) Both are immigrants in America.

c) Regularly update and publish videos on their YouTube Channels.

d) Have their own TV programme in Astro Naura Channel.

It is hoped that by choosing speakers who possess many similarities can reduce the external factors that might influence the metaphor usage by both speakers in their speeches.

\section{Data Collection}

Two corpora were collected comprising of speeches from the domain of Islamic motivational speech published on the speakers' official YouTube Channels: (a) Yasmin Mogahed https://www.youtube.com/user/YasminMogahedOnline; and (b) Nouman Ali Khan https://www.youtube.com/user/BayyinahInstitute. For ease of reference, the corpus of Nouman Ali Khan's speeches is denoted to as NAK Corpus, while corpus of Yasmin Mogahed's speeches is referred to as YM Corpus. The speeches were transcribed by using the 'dictate' function available in Google Doc. The transcripts were then manually checked for their accuracy before being converted into .txt format so they are compatible to be used in \#LancsBox 5.0 software. The dimension of the corpora is presented in Table 3.1. 
International Journal of Modern Languages and Applied Linguistics e-ISSN: 2600-7266

Table 3.1: Dimension of NAK Corpus and YM Corpus

\begin{tabular}{c|ccc} 
Corpus & Tokens & Types & Texts \\
\hline NAK & 24398 & 2565 & 4 \\
YM & 22622 & 2107 & 4
\end{tabular}

By using \#LancsBox 5.0, keywords list was generated from the wordlist comparison of both NAK and YM corpora. This is executed to identify the salient key items or overused words in each corpus when being compared to one another. This helps the researcher to identify the linguistic items that worth to be analysed because it does not only a simple frequency counts of the words in the corpus, but it also involves statistical significance tests like chi-square test, t-test, and log-likelihood test (LL). Nevertheless, the current study makes use of log-likelihood (LL) value to determine which words are considered significant in the corpus. McEnery and Hardie (2012) believes that the LL value must be over 7.0 for a word to be considered salient. Thus, any words that have the LL value more than 7.0 are considered as significant in the corpus. Table 3.2 displays the keyword list of YM corpus and NAK corpus when the wordlists have been compared to one another.

Table 3.2: Salient keywords in YM and NAK corpora

\begin{tabular}{|c|c|c|c|c|}
\hline No. & $\begin{array}{l}\text { Keywords + } \\
\quad(Y M)\end{array}$ & $L L$ & $\begin{array}{l}\text { Keywords - } \\
(\text { NAK })\end{array}$ & $L L$ \\
\hline 1 & SWT & 160.98 & YUSOF & 60.36 \\
\hline 2 & HEART & 73.57 & SUN & 45.93 \\
\hline 3 & POLICE & 48.29 & EVIL & 45.93 \\
\hline 4 & ${ }_{\mathrm{N}}$ FOUNDATIO & 42.44 & SYIRIK & 40.68 \\
\hline 5 & HEALTHY & 40.58 & BELIEVE & 40.54 \\
\hline 6 & CHILD & 37.77 & LIGHT & 35.11 \\
\hline 7 & TYPE & 36.38 & MOON & 27.56 \\
\hline 8 & FOCUS & 36.38 & FEELINGS & 27.56 \\
\hline 9 & FEAR & 33.58 & AUTHORITY & 24.93 \\
\hline 10 & PAIN & 30.23 & ADVICE & 23.62 \\
\hline 11 & SOLID & 29.42 & RELIGION & 21.89 \\
\hline 12 & FILL & 29.27 & FAITH & 19.67 \\
\hline
\end{tabular}

To reduce the entries to a manageable size, only content words that have the possibilities to be metaphorical are kept. From 20 words with the highest Log Likelihood (LL) value, 12 content words were selected for further analysis after deducing the functional words. From the table, it is evident that the word 'SWT' is considered as the most salient keyword ( $\mathrm{LL}=160.98)$ in YM Corpus, while the words 'Yusof' is considered as the most salient keyword ( $L L=60.36)$ in NAK Corpus. Once the keywords of both corpora have been 
determined, the collocations of these key words were generated and analysis of the concordance lines were performed.

\section{Data Analysis}

Lists of collocations were generated to predetermine the signals of linguistic metaphors. Collocation is defined as words that systematically co-occur in a corpus "to create a range of cross-associations that can be visualized as networks of nodes and collocates" (Brezina, 2016, p.90). In other words, the collocation illustrates significant relationship between words used in a corpus using statistical evidence (Williams, 2001). In the current study, GraphColl feature in \#LancsBox 5.0 was used to generate collocation graphs for the selected salient key items. MI statistical test was used to measure the collocational strength as it is one of the most common statistical formulae used by researchers in corpus study (Cheng, 2012; Hunston, 2002). For the study, MI score which is 3.0 or above is considered as significant collocates (Hunston, 2002). Figure 3.1 displays a sample of collocation graph generated by \#LancsBox 5.0 based on MI measurement.

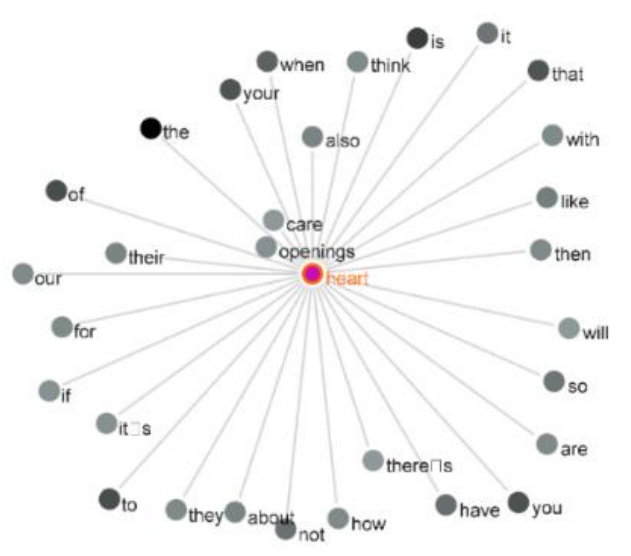

Figure 3.1: GraphColl of 'heart' generated by \#LancsBox 5.0

Figure 3.1 shows the co-occurring words that were significantly associated with 'heart' (e.g. openings, care). I couldn't see the figure clearly to look at the significance. Oxford Learner's Dictionary was used to detect semantic tension in the identified statistically significant collocates. The word 'openings' is highly associated with 'heart', indicating semantic tension as 'heart' is described as having openings like a container or vessel. Due to this, 'heart' is taken into consideration for further analysis as not only it has statistically meaningful collocations, but also has evidence of metaphorical expression/linguistic metaphor. Further analysis involves concordance analysis to certify linguistics metaphors used in the corpora. Concordance list permits the researcher to study the key words in context (KWIC) and understand how the words are used in the chosen corpus. Figure 3.2 presents a sample of concordance view of 'heart' generated by \#LancsBox 5.0 . 


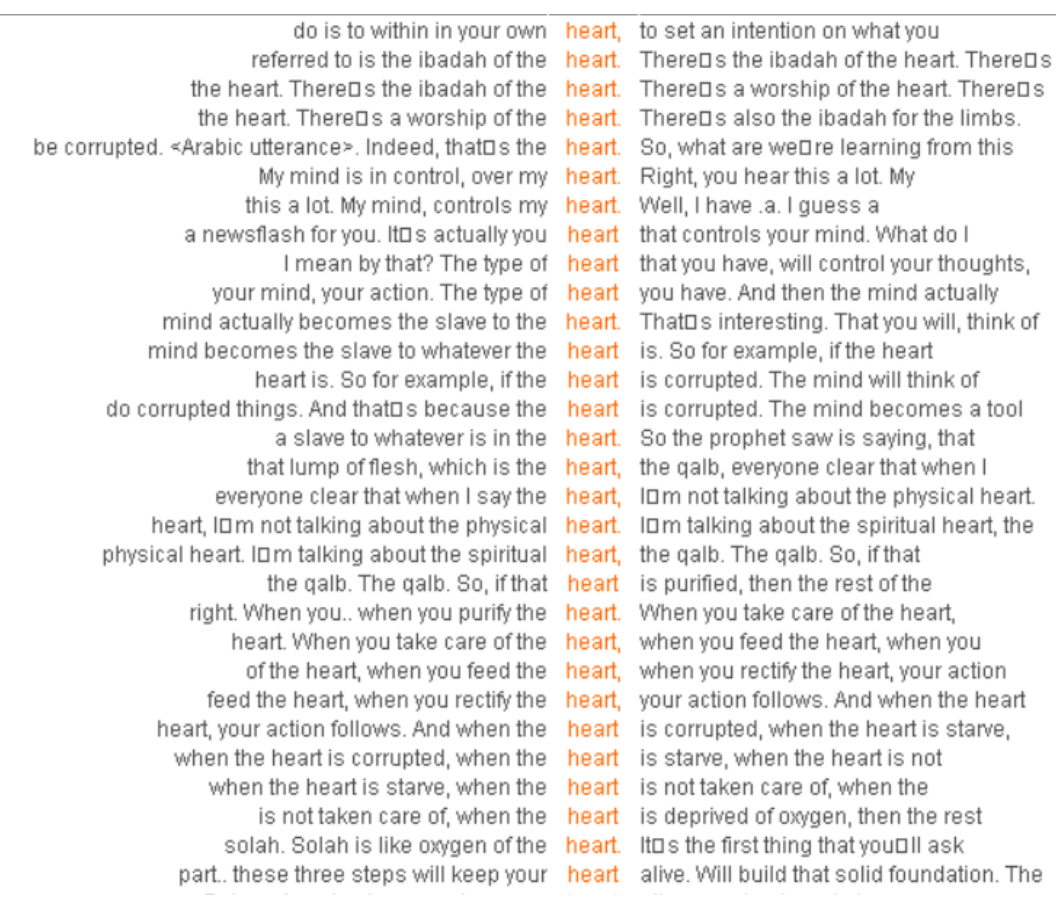

Figure 3.2: Concordance view of 'heart'

Subsequently, the identified linguistic metaphors that fall under the same theme/topic were mapped using conceptual mapping to identify conceptual metaphors used in both corpora (refer Figure 2.1). Once the metaphors in each corpus have been identified, the metaphors are grouped into the three main categories as proposed by Lakoff and Johnson (1980;2003): orientational, structural, and ontological (refer Table 2.1). Subsequently, the findings in both corpora are compared to learn the similarities and differences of metaphor usage between the speakers of different genders.

\section{Results and Discussion}

To recapitulate, the present research aims to: (i) identify whether Yasmin Mogahed and Nouman Ali Khan employ metaphors with similar frequency, and (ii) whether there are similarities or differences in the metaphors used by Yasmin Mogahed and Nouman Ali Khan. Hence the sub-topics of this section are dedicated to report the results and discuss them based on the developed research questions that lead to the aims of the study.

RQ 1: Do Yasmin Mogahed and Nouman Ali Khan employ metaphors with similar frequency?

With regards to the first research objective, it is revealed that Yasmin Mogahed employed a higher frequency of metaphorical expressions in her speeches as compared to Nouman Ali Khan's frequency of metaphorical expressions. From the collocation analysis, it can be identified that Yasmin has a higher number of significant collocates that might include the use of metaphorical expressions as compared to Nou- 
man's list of significant collocates. Table 4.1 displays the selected collocates in Yasmin Mogahed (henceforth YM) and Nouman Ali Khan (henceforth NAK) corpus.

Table 4.1: Selected collocates in YM and NAK corpus

\begin{tabular}{|c|c|c|c|c|c|c|c|}
\hline \multicolumn{4}{|c|}{ YM Corpus } & \multicolumn{4}{|c|}{ NAK Corpus } \\
\hline Keywords & & Collocate & MI & $\begin{array}{l}\text { Key- } \\
\text { words }\end{array}$ & & Collocate & MI \\
\hline SWT & $\begin{array}{l}\text { a) } \\
\text { b) } \\
\text { c) } \\
\text { d) } \\
\text { e) }\end{array}$ & $\begin{array}{l}\text { Positive } \\
\text { Opinion } \\
\text { Trust } \\
\text { Allah } \\
\text { Building*1 }\end{array}$ & $\begin{array}{l}7.00 \\
6.59 \\
6.49 \\
6.36 \\
5.66\end{array}$ & Evil $^{\# 1}$ & $\begin{array}{l}\text { a) } \\
\text { b) } \\
\text { c) } \\
\text { d) } \\
\text { e) }\end{array}$ & $\begin{array}{l}\text { Forbidding } \\
\text { Commanding } \\
\text { Wrong } \\
\text { Good } \\
\text { In }^{\# 1}\end{array}$ & $\begin{array}{l}9.32 \\
8.18 \\
7.24 \\
6.93 \\
3.33\end{array}$ \\
\hline Heart $* 2,3$ & $\begin{array}{l}\text { a) } \\
\text { b) }\end{array}$ & $\begin{array}{l}\text { Openings } * 2 \\
\text { Care } * 3\end{array}$ & $\begin{array}{l}8.31 \\
8.05\end{array}$ & Syirik $^{\# 1}$ & $\begin{array}{l}\text { a) } \\
\text { b) } \\
\text { c) } \\
\text { d) }\end{array}$ & $\begin{array}{l}\text { That } \\
\text { Do } \\
\text { Allah } \\
\text { In }^{\# 1}\end{array}$ & $\begin{array}{l}6.09 \\
5.78 \\
4.93 \\
4.92\end{array}$ \\
\hline $\begin{array}{l}\text { Founda- } \\
\text { tion*1 }\end{array}$ & $\begin{array}{l}\text { a) } \\
\text { b) } \\
\text { c) } \\
\text { d) } \\
\text { e) }\end{array}$ & $\begin{array}{l}\text { Build*1 } \\
\text { Building*1 } \\
\text { Solid*1 } \\
\text { Type } \\
\text { Allah }\end{array}$ & $\begin{array}{l}8.50 \\
8.16 \\
7.55 \\
7.28 \\
3.96\end{array}$ & Religion $^{\# 1}$ & $\begin{array}{l}\text { a) } \\
\text { b) } \\
\text { c) } \\
\text { d) }\end{array}$ & $\begin{array}{l}\text { Our } \\
\text { Your } \\
\text { Their } \\
\mathrm{In}^{\# 1}\end{array}$ & $\begin{array}{l}5.69 \\
5.20 \\
5.14 \\
3.10\end{array}$ \\
\hline Healthy*3 & $\begin{array}{l}\text { a) } \\
\text { b) } \\
\text { c) }\end{array}$ & $\begin{array}{l}\text { Fear*3 } \\
\text { Taqwa*3 } \\
\text { Allah }\end{array}$ & $\begin{array}{l}9.00 \\
9.00 \\
4.89\end{array}$ & Faith $^{\# 2}$ & & $\begin{array}{l}\text { Corrupted }{ }^{\# 2} \\
\text { Have }\end{array}$ & $\begin{array}{c}10.25 \\
5.27\end{array}$ \\
\hline Fear*3 & $\begin{array}{l}\text { a) } \\
\text { b) } \\
\text { c) } \\
\text { d) }\end{array}$ & $\begin{array}{l}\text { Healthy*3 } \\
\text { Taqwa*3 } \\
\text { Unhealthy*3 } \\
\text { Allah }\end{array}$ & $\begin{array}{l}9.00 \\
8.98 \\
8.81 \\
5.43\end{array}$ & & & & \\
\hline Solid*1,4 & $\begin{array}{l}\text { a) } \\
\text { b) } \\
\text { c) } \\
\text { e) }\end{array}$ & $\begin{array}{l}\text { Roots*4 } \\
\text { Tree*4 } \\
\text { Build*1 } \\
\text { Foundation*1 }\end{array}$ & $\begin{array}{l}8.97 \\
8.82 \\
8.44 \\
7.55\end{array}$ & & & & \\
\hline Fill $* 2$ & $\begin{array}{l}\text { a) } \\
\text { b) } \\
\text { c) } \\
\text { d) }\end{array}$ & $\begin{array}{l}\text { Emptiness*2 } \\
\text { Try } \\
\text { People } \\
\text { Allah }\end{array}$ & $\begin{array}{l}9.14 \\
8.20 \\
6.33 \\
4.50\end{array}$ & & & & \\
\hline
\end{tabular}

From the listed significant collocates, there are only a few statistically significant collocates that indicate metaphorically used words. Based on the list of selected collocates of YM corpus tabulated in Table 4.1, four (4) categories of potential metaphorical expressions can be determined. The categories of the potential metaphorical expressions in YM corpus are BUILDING*1, CONTAINER*2, HUMAN/LIVING ORGANISM*3, and TREE*4. Meanwhile, in NAK corpus, there are only two (2) categories of potential metaphorical expressions that can be predetermined from the collocation analysis. Based on Table 4.1, the predetermined categories of potential metaphorical expressions in NAK corpus are CONTAINER ${ }^{\# 1}$ and COMPUTER FILE $^{\# 2}$. These categories were determined by detecting semantic tension between the words in the collocates. This finding will help researchers to identify traces of metaphorical expressions in a corpus. Since collocation analysis is not enough to certify a word or phrase as a metaphorical expression, these collocates were 
further analysed by using qualitative analysis. This is performed by scrutinizing the keyword in its context in the concordance lines. From the concordance analysis, several conceptual metaphors have been identified in YM and NAK corpora.

\section{Conceptual Metaphors in YM Corpus}

a)

\section{BUILDING Metaphor}

Table 4.1 exemplifies that the word 'building' recurs several times in YM corpus for the words 'SWT', 'foundation', and 'solid'. This indicates BUILDING metaphor could be a dominant metaphor in YM corpus. Figure 4.1 presents the GraphColl of the 'SWT', 'foundation', and 'solid' collocates.
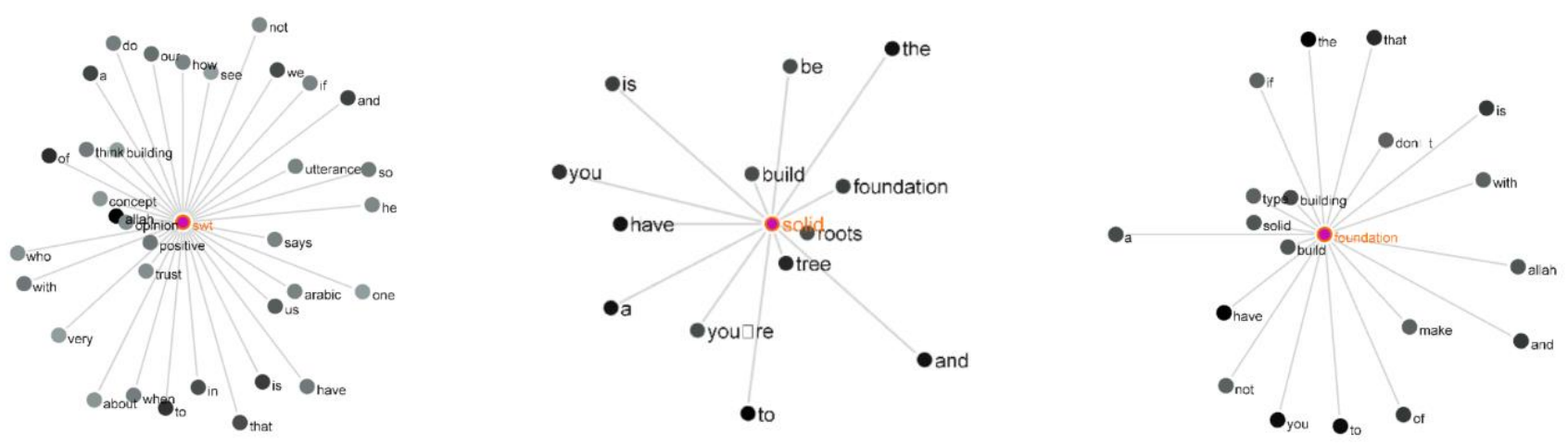

Figure 4.1: GraphColl of 'SWT', 'foundation', and 'solid' collocates

From the GraphColl in Figure 4.1, the word 'SWT', that is commonly used with 'Allah', is statistically significantly associated with the word 'positive'(MI=7.00), 'opinion'(MI=6.59), 'trust'(MI=6.49), and 'building' $(\mathrm{MI}=5.66)$. The association with the word 'building' indicates an evidence of semantic tension, a signal for metaphorical expression. As the dictionary definition of the word 'build' is "to make something, especially a building, by putting parts together" (Oxford Learner's Dictionary, 2020), it indicates a physical construction of a certain structure. Since this word is highly associated with 'SWT' that represents an abstract entity, God, it must be further examined to seek traces of metaphorical expression. From the concordance analysis it can be certified that the word' building' is used to describe a relationship or attachment to God. For example:

“...we're not talking about building an attachment to Allah..."

“...you're talking to Allah SWT that you're building a relationship with Allah..” 
This evidence highlights that Yasmin described humans' relationship with God or attachment to God as a physical structure, BUILDING. She also described this attachment or relationship can be built layer by layer like a building structure that has many floors. In addition, as presented in Figure 4.1, it is also evident that the word 'foundation' and 'solid' are both highly associated with one another and also with the word 'build' or 'building'. From the concordance analysis, it is revealed that the word 'building' and 'foundation' refer to the relationship with Allah SWT. For instance:

\footnotetext{
“...how you build a a a stronger foundation with Allah.”

“... because you're building without a solid foundation ...”

"...you have to build the foundation in the love of Allah."
}

By using the words 'solid' and 'foundation', Yasmin was describing that in order to have a strong relationship or attachment with God, humans must have a solid or strong foundation just like how a well-built building must have solid underground base underneath it. Thus, this certifies the existence of RELATIONSHIP WITH GOD IS A BUILDING metaphor, a structural metaphor (refer Table 2.1).

b) CONTAINER Metaphor

The second category of metaphorical expression that was predetermined in the collocate analysis is CONTAINER metaphor. Figure 4.2 presents the GraphColl of the 'heart' collocates.

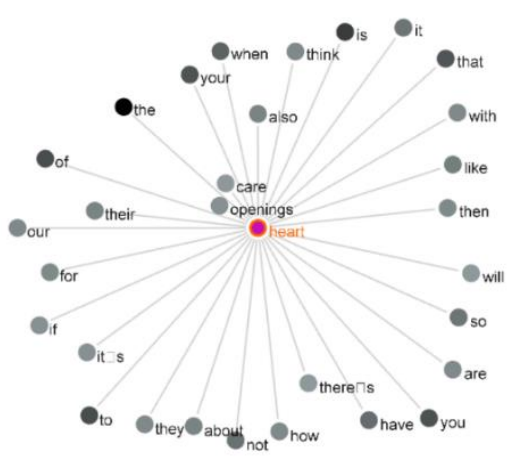

Figure 4.2: GraphColl of 'heart' collocates

From the GraphColl in Figure 4.2, the word 'heart' is statistically significantly associated with the word 'openings' (MI=8.31). The association between 'heart' (spiritual heart) with the word 'openings' indicates an evidence of semantic tension. 'Openings' is defined as 'a space or hole that somebody/something can pass through" (Oxford Leaner's Dictionary, 2020). This shows that Yasmin de- 
scribes the abstract entity of a spiritual 'heart' as a physical entity such as a container. This can be further certified with the findings from concordance analysis:

\section{"Those are the openings to the heart." \\ "What are the openings to the heart."}

The concordance analysis also reveals another evidence of signal word of CONTAINER metaphor in describing the spiritual 'heart':

\footnotetext{
“...is to within in your own heart, to set an intention..."

"... a slave to whatever is in the heart..."
}

As the preposition 'in' refers to "at a point within an area or a space/within a shape of something" (Oxford Learner's Dictionary, 2020), it further strengthens the notion that Yasmin used CONTAINER metaphor in describing a spiritual 'heart' in her discourse. Thus, the findings certify the evidence of HEART IS A CONTAINER metaphor, an ontological metaphor (refer Table 2.1).

From Table 4.1, it can also be seen that Yasmin used another CONTAINER metaphor to describe the abstract entity of 'emptiness'. Figure 4.3 illustrates that the word 'emptiness' is statistically significantly associated with the word 'fill' with MI value of 9.14 .

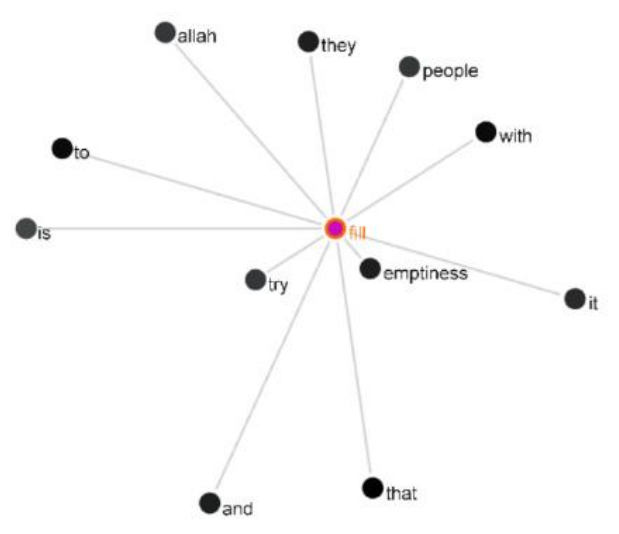

Figure 4.3: GraphColl of 'fill' collocates

The concordance analysis further certifies the association between these words as the expression recurs several times. For example: 
“...we go through this life trying to fill that emptiness."

"Only Allah can fill that emptiness inside."

"... a lot of whatever it is to fill that emptiness..."

The word 'emptiness' is defined as "a feeling of being sad because nothing seems to have any value" or "the fact that there is nothing or nobody in a place" (Oxford Leaner's Dictionary, 2020), thus it refers to an abstract entity. As the word 'fill' is defined as "to make something full of something; to become full of something" (Oxford Learner's Dictionary, 2020), Yasmin described the abstract entity 'emptiness' as a physical entity like a CONTAINER that can be filled. Hence, this certifies the evidence of another ontological metaphor (refer Table 2.1), EMPTINESS IS A CONTAINER.

c) HUMAN/LIVING ORGANISM Metaphor

The third category of metaphorical expression that was predetermined in the collocate analysis is HUMAN/LIVING ORGANISM metaphor. Figure 4.2 in the previous sub-topic displays the GraphColl of the 'heart' collocates which shows significant association with the word 'care' $(\mathrm{MI}=8.05)$. 'Care' is defined as “take care of somebody/something/yourself” (Oxford Learner's Dictionary, 2020), which means Yasmin described the spiritual 'heart' as a physical entity like a HUMAN/LIVING ORGANISM that can be taken care of. To further certify this notion, concordance analysis was executed, and the findings revealed that there were other words being used that also linked 'heart' specifically as a HUMAN/LIVING ORGANISM.

"...when the heart is starved, when the heart..."

"... when you feed the heart..."

"...these three steps will keep your heart alive."

"...when the heart is deprived of oxygen ..."

From the concordance list, Yasmin described the spiritual 'heart' as having the ability to 'starve' and can be 'fed' like a HUMAN/LIVING ORGANISM. She also described 'heart' as being 'alive' and 'deprived of oxygen' just like how a HUMAN/LIVING ORGANISM can. This reveals an evidence of semantic tension which reflects a metaphorical expression in the phrase. Thus, this certifies the existence of another metaphor of 'heart', HEART IS A HUMAN/LIVING ORGANISM, a structural metaphor (refer Table 2.1).

Apart from this, Yasmin also used the same structural metaphor to describe other abstract entity, 'fear'. Figure 4.4 displays the GraphColl of the word 'fear'. 


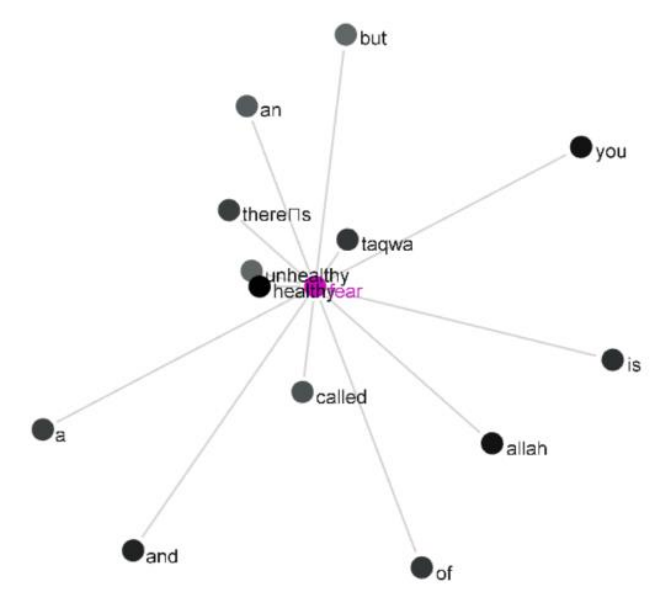

Figure 4.4: GraphColl of 'fear' collocates

Figure 4.4 shows significant association of 'fear' with the word 'healthy' (MI=9.00) and 'unhealthy' $(\mathrm{MI}=8.81)$. The concordance analysis reveals how the word 'healthy' and 'unhealthy' were used with the word 'fear'.

\footnotetext{
“...there's a healthy fear, and there's an unhealthy fear..."

"But the healthy fear is called taqwa."

"So, healthy fear will motivate us to get closer..."

"That is born from an unhealthy fear that was planted into that child."
}

From the concordance list, it can be seen that 'fear' is described as being 'healthy' and 'unhealthy' like how a HUMAN/LIVING ORGANISM can be. 'Healthy' is defined as "having good health and not likely to become ill” (Oxford Learner's Dictionary, 2020), which means Yasmin described 'fear', an abstract entity, as a physical entity like a HUMAN/LIVING ORGANISM that has a health state. The word 'healthy' causes semantic tension as it is usually used to describe a state of a either a HUMAN or LIVING ORGANISM. Nevertheless, in YM corpus it is highly associated with 'fear' that is abstract and intangible. Thus, this certifies the existence of another structural metaphor (refer Table 2.1) using HUMAN/LIVING ORGANISM, FEAR IS A HUMAN/LIVING ORGANISM.

d) TREE Metaphor

The final category of metaphorical expression that was predetermined in the collocate analysis is TREE metaphor. Figure 4.5 displays the GraphColl of the word 'solid'. 


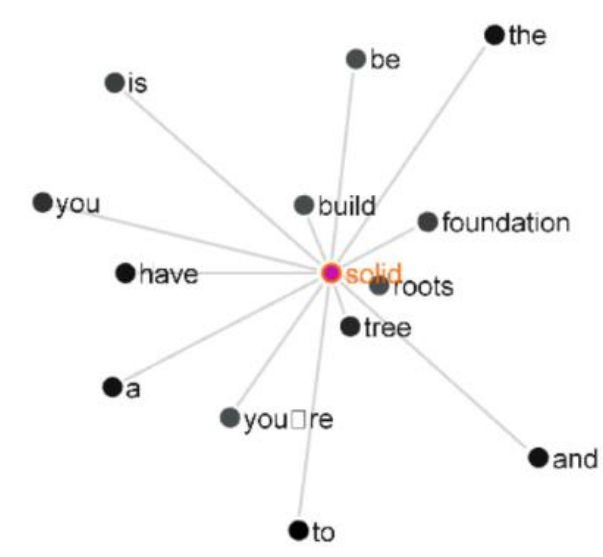

Figure 4.5: GraphColl of 'solid' collocates

As can be seen in Figure 4.5, the word 'solid' is seen to be highly associated with the word 'roots' $(\mathrm{MI}=8.97)$ and 'tree' $(\mathrm{MI}=8.82)$. However, the evidence of semantic tension is not clear because there is no clear abstract entity being associated in the collocates. Once the concordance analysis was executed, the findings discovered that the phrase containing these words are metaphorical.

"...to be firm in istiqamah is if you look at a solid tree."

"A solid tree has istiqamah because it stands firm when the wind blows."

“...you're not gonna have a solid deep root."

From the concordance lines, it can be seen that Yasmin used words like tree and deep root to describe istiqamah. The word istiqamah means to go straight into the right direction, acting rightly, allowing no deviation or it can be translated as steadfastness (https://deenwayoflife.wordpress.com/2011/01/05/istiqamah/). Thus, istiqamah is an abstract entity and Yasmin used words like tree and deep root, a physical entity. This friction indicates a semantic tension between the two notions that are being compared. Hence, this signals the evidence of another structural metaphor (refer Table 2.1), ISTIQAMAH IS A TREE.

\section{Conceptual Metaphors in NAK Corpus}

a) CONTAINER Metaphor

Table 4.1 exemplifies that the word preposition 'in' recurs several times in NAK corpus for the words 'evil, 'syirik', and 'religion'. This indicates CONTAINER metaphor could be a dominant metaphor in NAK corpus. Figure 4.6 presents the GraphColl of the 'evil' collocates. 


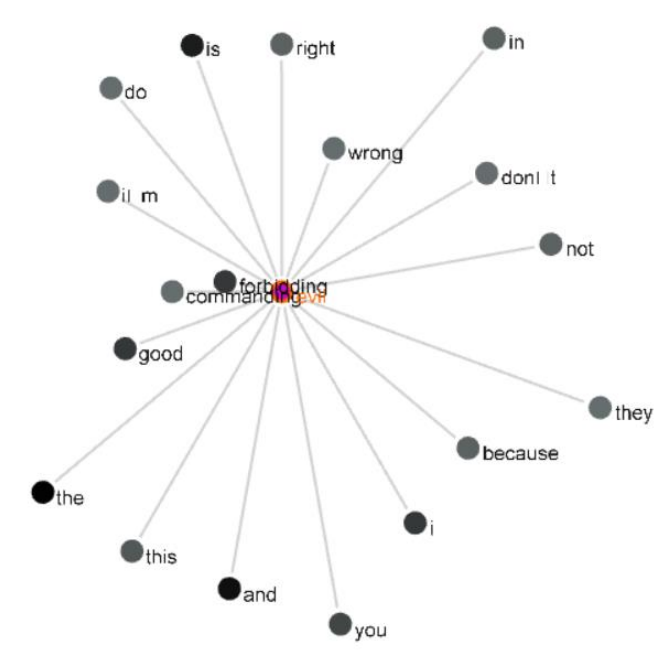

Figure 4.6: GraphColl of 'evil' collocates

As can be seen in Figure 4.5, even though the word 'evil' is seen to be highly associated with the word 'forbidding' $(\mathrm{MI}=9.32)$ and 'commanding' $(\mathrm{MI}=8.18)$, there is no evidence of semantic tension which certifies these words are metaphorical. The concordance analysis certifies this notion to be true as Nouman was explaining a concept of commanding good and forbidding evil (amar makruf nahi mungkar). Thus, these collocates are not metaphorical. However, there is a significant association between the word 'evil' with the preposition 'in' $(\mathrm{MI}=3.33)$ that indicates a semantic tension. The concordance lines below certify this notion.

"...if someone is engaged in evil, accepting them..."

"This is evil in the evil itself."

'Evil', which is defined as "a force that causes bad things to happen; morally bad behaviour" (Oxford Learner's Dictionary, 2020), is an abstract entity. When Nouman used 'in' with 'evil', it indicates the idea of 'evil' as a physical entity that has an area or a space and in a shape of something, like a CONTAINER. Hence, it is certified that there is an ontological metaphor (refer Table 2.1), EVIL IS A CONTAINER, in NAK corpus.

Apart from 'evil', there is also another possible CONTAINER metaphor identified in 'syirik' collocates. Figure 4.7 displays the GraphColl of 'syirik' collocates. 


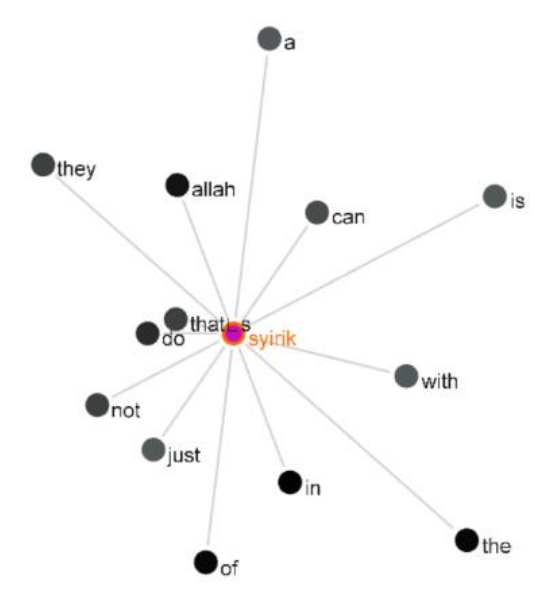

Figure 4.7: GraphColl of 'syirik' collocates

As can be seen in Figure 4.7, the word 'syirik' is seen to be highly associated with the word 'that' $(\mathrm{MI}=6.09)$ and 'do' $(\mathrm{MI}=5.78)$. Nevertheless, there is no evidence of semantic tension that shows these words are metaphorically used in NAK corpus. Thus, these collocates are not considered metaphorical. However, there is a significant association between the word 'syirik' with the preposition 'in' $(\mathrm{MI}=4.92)$ that might indicate the use of CONTAINER metaphor, but the concordance lines below disprove this notion.

\section{"That's not syirik in the authority of Allah." \\ "That's not syirik in the might of Allah"}

From the concordance lines, even though the preposition 'in' is statistically significant with the word 'syirik', in its context, it is not used to describe 'syirik' itself but the authority and might of Allah. Thus, these words are considered non-metaphorical.

Lastly, the 'religion' collocates also indicate the signal of CONTAINER metaphor. Figure 4.8 presents the GraphColl of 'religion' collocates. 


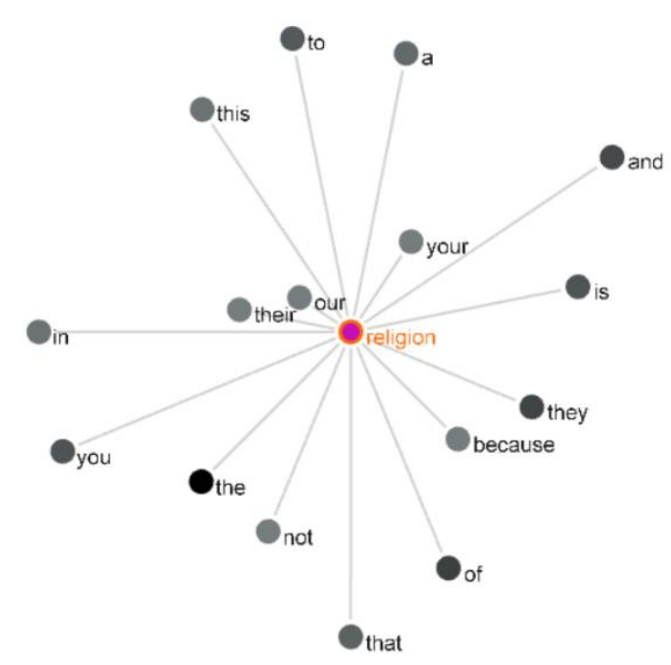

Figure 4.8: GraphColl of 'religion' collocates

In Figure 4.8, the word 'religion' is highly associated with the pronouns 'our' (MI=5.68), 'your' $(\mathrm{MI}=5.2)$, and 'their' $(\mathrm{MI}=5.14)$. Nonetheless, there is no evidence of semantic tension that shows these pronouns are metaphorically used in NAK corpus. Thus, these collocates are not considered metaphorical. However, there is a significant association between the word 'religion' with the preposition 'in' $(\mathrm{MI}=3.10)$ that might indicate the use of CONTAINER metaphor and the concordance lines below certify this notion.

\footnotetext{
"...you know a mandate in the religion?"

“...certain values that are timeless in our religion."

“...you know in whatever religion it maybe."

“...the most knowledgeable in other religion..."
}

'Religion', which is defined as "the belief in the existence of a god or gods, and the activities that are connected with the worship of them, or in the teachings of a spiritual leader" (Oxford Learner's Dictionary, 2020), is an abstract entity. When Nouman used 'in' when describing the idea of 'religion', it indicates the idea of 'religion' as a physical entity that has an area or a space and in a shape of something, like a CONTAINER. Hence, it is certified that there is another ontological metaphor (refer Table 2.1), RELIGION IS A CONTAINER in NAK corpus.

b) COMPUTER FILE Metaphor

The final category of metaphorical expression that was predetermined in NAK corpus is COMPUTER FILE metaphor based on 'faith' collocates. Figure 4.9 presents the GraphColl of the 'faith' collocates. 


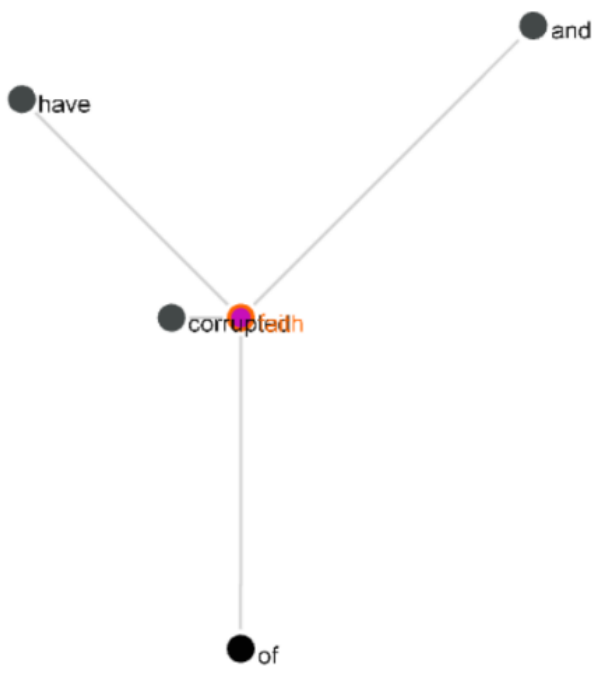

Figure 4.9: GraphColl of ‘faith’ collocates

In Figure 4.9, it can be seen that the word 'faith' is highly associated with the word 'corrupted' $(\mathrm{MI}=10.25)$. In order to analyse this association further, the concordance lines below were examined to learn how the words are used in their context.

\footnotetext{
“...I called it anatomy of corrupted faith and the reason..."

"Why corrupted faith? Because actually every human..."

"...this this is the anatomy of corrupted faith."

“... and these are corruptions in our faith."
}

From the concordance lines, it can be seen Nouman used the words 'corrupted' and 'corruptions' in describing 'faith'. It can be determined that there is a semantic tension between the word 'faith' and 'corrupted'. 'Faith' is defined as a "strong religious belief' (Oxford Learner's Dictionary, 2020), indicating the existence of an abstract entity. Meanwhile, 'corrupted' is defined as "to have a bad effect on somebody or corrupt something to change the original form of something" (Oxford Learner's Dictionary, 2020) which indicates the word may be literally used. However, the word 'corrupted' can also mean "to cause mistakes to appear in a computer file, with the result that the information in it is no longer correct" (Oxford Learner's Dictionary, 2020). This definition causes semantic friction as the idea of 'faith' can be 'corrupted' like an error in a computer file indicates a sign of metaphorical expression. Thus, this certifies a structural metaphor (refer table 2.1), FAITH IS A COMPUTER FILE in NAK corpus. 
Apart from that, the concordance analysis also discovers an interesting use of the word 'anatomy' in describing 'faith'. However, the word 'anatomy' does not appear in the 'faith' collocates, hence, it will not be further analysed as the words are not statistically significantly associated.

RQ2: Are there similarities or differences in the metaphors used by Yasmin Mogahed and Nouman Ali $\underline{\text { Khan? }}$

With regards to the second research objective of the study, the findings revealed that there are similarities and differences in the metaphors used by Yasmin Mogahed and Nouman Ali Khan. When the conceptual metaphors have been identified in both corpora, they are categorised into three main types of conceptual metaphors. Table 5.1 below tabulates the conceptual metaphors identified in both YM and NAK corpora.

Table 5.1: Conceptual metaphors in YM and NAK corpus

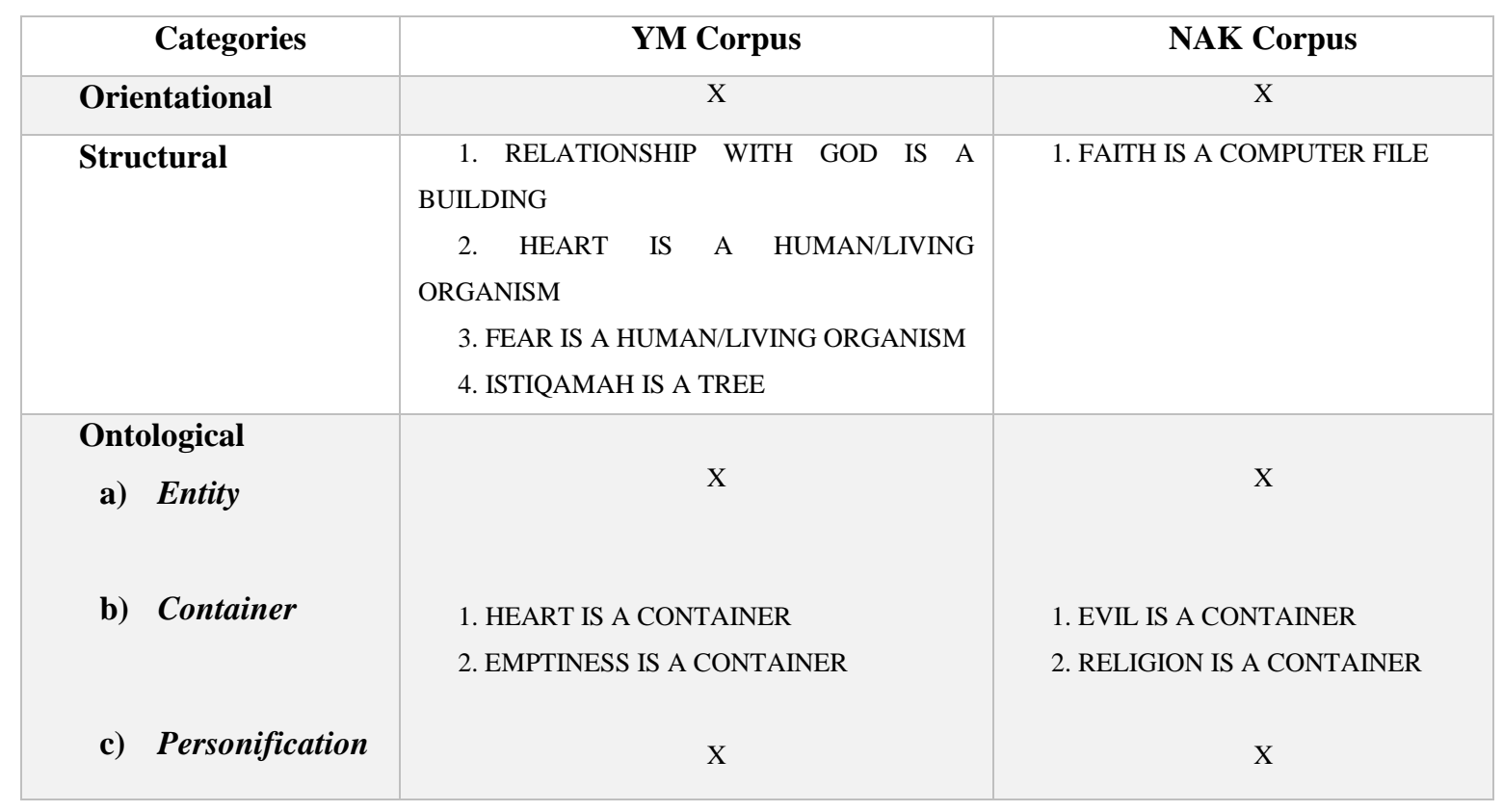

From the table, it is evident that Yasmin's usage of metaphors is more distinct than Nouman's. Both speakers do not use any orientational metaphor and two types of ontological metaphors: ENTITY and PERSONIFICATION, in their discourse. Apart from that, both of them also used the same type of conceptual metaphors: structural and one of the three types of ontological metaphor, CONTAINER metaphor. Even though both of the speakers used structural metaphor, there is no similarity in terms of the kind of metaphors used. For example, Yasmin used BUILDING, HUMAN/LIVING ORGANISM, and TREE metaphors to describe 'relationship with God', 'heart', 'fear', and 'istiqamah', while Nouman only used COMPUTER FILE metaphor to describe 'faith'. In terms of the choice of metaphors used by Yasmin, it is interesting to learn that Yasmin prefers to use metaphors associated with living thing and nature (e.g. HUMAN/LIVING ORGANISM 
and TREE). Her choice of metaphor might be influenced with the common metaphors found in the Holy Qur'an which link to natural phenomena: RAIN, MOUNTAIN, WIND, LIGHT, and DARKNESS (Mohamed, 2014). Meanwhile, Nouman's choice of COMPUTER FILE might be from his own personal choice. For CONTAINER metaphor, they used it for different abstract entity. For instance, Yasmin used CONTAINER metaphor to describe 'heart' and 'emptiness', while Nouman used it to describe 'evil' and 'religion'. Yasmin's use of HEART IS A CONTAINER metaphor again seems to be influenced from the metaphor used in the Qur'an. The exact same metaphor can be found in Al-Baqarah 93 in the clause "and their hearts became filled with the love of the calf." (Nurbayan, 2019) which indicates the spiritual 'heart' can be 'filled' with something like a container conceptualising HEART IS A CONTAINER metaphor. However, Yasmin used different terms (openings' and 'in') in her metaphorical expression. In addition, it is apparent that the variety of metaphors used by Yasmin is more diverse (BUILDING, HUMAN/LIVING ORGANISM, TREE, and CONTAINER metaphors) as compared to Nouman that only uses COMPUTER FILE and CONTAINER metaphors.

\section{Conclusion}

To sum up, the findings of the current study have answered the research questions developed earlier. The first research question is to investigate whether both speakers of different genders employed similar frequency of metaphors in their discourse. It can be deduced that both speakers of different genders did use metaphors in their discourse, nevertheless, there is an apparent difference in terms of the frequency of metaphors used by each speaker. It is learnt that Yasmin used a higher frequency of metaphors compared to Nouman. This is evident from the results in the collocation analysis in YM corpus that show seven collocates ('SWT', 'heart', 'foundation', 'healthy', 'fear', 'solid', and 'fill') were predetermined to have signals of metaphorical expressions as compared to NAK corpus that only has four collocates ('evil', 'syirik', 'religion', and 'faith') with signals of metaphorical expressions. This is further supported with the findings from the concordance analysis which revealed six metaphors were identified in YM corpus compared to only three metaphors identified in NAK corpus.

In relation to the second research question that seeks to examine whether there are similarities or differences in the metaphors used by the speakers of different genders, the findings revealed that both speakers do not use any orientational metaphor and two types of ontological metaphors: ENTITY and PERSONIFICATION, in their discourse. Apart from that, both of them also used the same type of conceptual metaphors: structural and one of the three types of ontological metaphor, CONTAINER metaphor. 
International Journal of Modern Languages and Applied Linguistics e-ISSN: 2600-7266

Finally, it can be concluded that the corpus-based approach is very helpful in the early detection of metaphors through collocation analysis. Nevertheless, manual analysis of the concordance lines still needs to be executed to certify the evidence of metaphorical language in a discourse. The case study shows metaphor and gender are closely connected in Islamic discourse and this complex topic needs to be further investigated in future research. However, future studies on a bigger population with diverse samples of both male and female speakers in Islamic motivational speeches corpus should be executed to learn possible metaphorical linguistic patterns between different genders. The implication of choice of metaphors by male and female speakers should also be investigated to further understand how speakers of different genders use metaphors in their speeches.

\section{References}

Abdulmoneim, S. M. B. (2006). The Metaphorical Concept "Life is a Journey" in the Qur'an: A cognitivesemantic Analysis. Metaphorik.de, 94-132.

Adnan, N. B. (2014). A Corpus-Based Study of Time Metaphors in the Text Simplification of 'Around the World In 80 Days'. PhD Thesis. University of Malaya, Kuala Lumpur.

Ahrens, K. \& Jiang, M. (2020). Source Domain Verification Using Corpus-based Tools. Metaphor and Symbol, 35(1), 43-55, DOI: 10.1080/10926488.2020.1712783

Alkhodari, F. T. \& Habil, H. (2019). Analysis of Zakir Naik’s Persuasion Discourse. International Journal of Engineering and Advanced Technology (IJEAT), Vol. 8 (5).

Battle. (2020). In Oxford Learner's Dictionary. Retrieved from https://www.oxfordlearnersdictionaries.com/definition/english/battle_1?q=battle

Boers, F. (2000). Metaphor awareness and vocabulary retention. Applied Linguistics, 21(4), 553-571.

Brezina, V. (2016). Collocation networks. In Baker, P., \& Egbert, J. (Eds.), Triangulating Methodological Approaches in Corpus Linguistic Research (pp. 102-119). New York/London: Routledge.

Brezina, V., Weill-Tessier, P., \& McEnery, A. (2020). \#LancsBox v. 5.x. [software]. Available at: http://corpora.lancs.ac.uk/lancsbox.

Build. (2020). In Oxford Learner's Dictionary. Retrieved from

https://www.oxfordlearnersdictionaries.com/definition/english/build_1?q=build

Cameron, L. (2003). Metaphor in educational discourse. London: Continuum.

Care. (2020). In Oxford Learner's Dictionary. Retrieved from https://www.oxfordlearnersdictionaries.com/definition/english/care_1?q=care

Charteris-Black, J. (2004). Corpus approaches to critical metaphor analysis. Houndmills, Basingstoke;

Hampshire, New York: Palgrave Macmillan.

Cheng, W. (2012). Exploring corpus linguistics: Language in action. London/New York: Routledge. 
Cortazzi, M., \& Jin, L. (1999). Bridges to learning: Metaphors of teaching, learning and language. In Cameron, L. \& Low, G. D. (eds.), Researching and applying metaphor (pp. 149-176). Cambridge: Cambridge University Press.

Corrupted. (2020). In Oxford Learner's Dictionary. Retrieved from https://www.oxfordlearnersdictionaries.com/definition/english/corrupt_2?q=corrupted

Dincel, B. K. (2019). Metaphors on the Concepts of "Reading" and "Listening" Created by the Secondary School Students. Journal of Education and Learning, 8(1). doi:10.5539/jel.v8n1p238

El-Sharif, A. (2011). A Linguistic Study of Islamic Religious Discourse: Conceptual Metaphors in the Prophetic Tradition, $\mathrm{PhD}$ Thesis. Queen Mary, University of London.

Emptiness. (2020). In Oxford Learner's Dictionary. Retrieved from https://www.oxfordlearnersdictionaries.com/definition/english/emptiness?q=emptiness

Evil. (2020). In Oxford Learner's Dictionary. Retrieved from https://www.oxfordlearnersdictionaries.com/definition/english/evil_1?q=evil

Faith. (2020). In Oxford Learner's Dictionary. Retrieved from https://www.oxfordlearnersdictionaries.com/definition/english/faith_1?q=faith

Gibbs, R. (1994): The Poetics of Mind: Figurative Thought, Language, and Understanding. Cambridge: Cambridge University Press.

Gibbs, R. W. (2011). Evaluating conceptual metaphor theory. Discourse Processes, 48(8), 529-562.

Goatly, A. (2007). Washing the brain: Metaphor and hidden ideology. Amsterdam: John Benjamin.

Hellinger, M. 2006. 'Why Merkel is not Enough: On the Representation of Fe/male Politicians in German Newspapers'. Paper presented at the International Gender and Language Association conference, Valencia, Spain, 8-10 November.

Hercberg, E.N. 2007. 'The 2007 Presidential Campaign in France: Language, Media, and Sexual Discrimination'. Paper presented at the Women, Power and the Media conference, Aston University, Birmingham, UK, 15-16 September.

Healthy. (2020). In Oxford Learner's Dictionary. Retrieved from https://www.oxfordlearnersdictionaries.com/definition/english/healthy?q=healthy

Holyoak, K.J. \& Stamenkovi'c, D. (2018). Metaphor Comprehension: A Critical Review of Theories And Evidence. American Psychological Association. Psychological Bulletin, 144(6), 641-671. http://dx.doi.org/10.1037/bul0000145

Hunston, S. (2002). Methods in corpus linguistics: Beyond the concordance line. In Hunston, S. (Ed.), Corpora in Applied Linguistics (pp. 67-95). Cambridge: Cambridge University Press. 
International Journal of Modern Languages and Applied Linguistics e-ISSN: 2600-7266

In. (2020). In Oxford Learner's Dictionary. Retrieved from https://www.oxfordlearnersdictionaries.com/definition/english/in_1?q=in

Ismail, A. I. (2017). A Rhetorical Analysis of Selected Speeches of Dr. Zakir Naik. Master Thesis. Gombak, International Islamic University Malaysia.

Istiqamah. (2020). In Deen Way of Life. Retrieved from https://deenwayoflife.wordpress.com/2011/01/05/istiqamah/

Jeong, S. (2008) Visual Metaphor in Advertising: Is the Persuasive Effect Attributable to Visual Argumentation or Metaphorical Rhetoric? Journal of Marketing Communications, 14(1), 59-73, DOI: $10.1080 / 14697010701717488$

Kamberi, L. (2014). Using metaphors in language teaching and learning. European Journal of Research on Education, 2014, Special Issue: Contemporary Studies in Education, 92-97.

Koller, V. 2004. 'Businesswomen and War Metaphors: "Possessive, Jealous and Pugnacious". Journal of Sociolinguistics, 8(1), 3-22.

Koller, V. \& Semino, E. (2009). Metaphor, Politics and Gender: A Case Study from Germany. In (Ed.) Ahrens, K., Politics, Gender and Conceptual Metaphors, pp. 9-35. New York: Palgrave McMillan.

Kövecses, Z. (2005). Metaphor in culture. Universality and variation. New York/Cambridge: Cambridge University Press.

Kövecses, Z. (2010). Metaphor: A Practical Introduction. Cary, GB: Oxford University Press, USA.

Kövecses, Z. (2011). Methodological issues in conceptual metaphor theory. S. Handl, \& H. Schmid (Eds.) Cognitive Linguistics Research [CLR]: Windows to the Mind: Metaphor, Metonymy and Conceptual Blending.

Krennmayr, T. (2011). Metaphors in Newspaper. Lot Trans 10, the Netherlands.

Ladika, A. R. (2018). The Analysis of Figurative Language Used by Dr. Zakir Naik. Indonesia: Jambi University.

Lakoff, G. (1993). The contemporary theory of metaphor. In O. Andrew (Ed.), Metaphor and thought (2nd ed.). Cambridge, UK: Cambridge University Press.

Lakoff, G. \& Johnson, M. (1980). Metaphors we live by. Chicago; London: University of Chicago Press.

Lakoff, G. \& Johnson, M. (2003). Metaphors We Live By. London: The University Chicago Press.

Larson, M. L. (1984). Meaning-Based Translation: A Guide to Cross Language Equivalent. America: University Press of America.

Lenard, D.B. \& Ćosić, N. (2017). The Analysis of Metaphors and Metonymies in Political Speeches-A Case Study of the Former Croatian Prime Minister Ivo Sanader. ELR Journal, 61-81. 
Maula, A. (2016). A Metaphor Translation of the Qur'An: A Comparative Analytical study between Abdullah Yusuf Ali and Marmaduke Pickthall. Indonesian Journal of Islamic Literature and Muslim Society, 1(2), 129-148. DOI: 10.22515/islimus.v1i2.424

McEnery, T., \& Hardie, A. (2011). Corpus linguistics: Method, theory and practice. Cambridge, UK: Cambridge University Press.

Mohamed, M. 2014. The metaphor of nature in the Holy Qur'an: A critical metaphor analysis (CMA). Journal of Arabic and Human Sciences. 270(1688), 1-37.

Musolff, A. (2004). Metaphor and political discourse: Analogical reasoning in debates about Europe. Basingstoke: Palgrave Macmillan.

Mustapha, M. \& Abdul Razak, A. M. (2019). A Critical Appraisal of Zakir Naik's Islamic Evangelism. International Journal of Islamic Thought, 15, 71-83. https://doi.org/10.24035/ijit.15.2019.007

Noureldin, M. A., \& Kaigama, A. (2015). Investigating Metaphor Used in Surah Al-Hadid to Convey Abstract Meaning. Australian Journal of Basic and Applied Sciences, 9(11), 24-27.

Nurbayan, Y. (2019). Metaphors in the Quran and its translation accuracy in Indonesian. Indonesian Journal of Applied Linguistics, 8(3), 710-715. http://dx.doi.org/10.17509/ijal.v8i3.15550

Openings. (2020). In Oxford Learner's Dictionary. Retrieved from https://www.oxfordlearnersdictionaries.com/definition/english/opening_1?q=openings

Partington, A. (2007). Metaphors, motifs and similes across discourse types: Corpus-assisted discourse studies (CADS) at work. In Stefanowitsch, A. and Gries, S.T. (eds.) Corpus-based Approaches to Metaphor and Metonymy (Vol. 171). Berlin: Walter de Gruyter. p. 267.

Religion. (2020). In Oxford Learner's Dictionary. Retrieved from https://www.oxfordlearnersdictionaries.com/definition/english/religion?q=religion

Semino, E. (2008). Metaphor in discourse. New York: Cambridge University Press.

Semino, E. (2017) Corpus linguistics and metaphor. In Dancygier, B. (ed.) The Cambridge Handbook of Cognitive Linguistics. Cambridge: Cambridge University Press, pp. 463-76.

Semino, E. \& Steen, G. (2008). Metaphor in Literature. In Gibbs, R. W. Jr., The Cambridge Handbook of Metaphor and Thought. Santa Cruz: Cambridge University Press.

Semino, E., Demjén, Z., Demmen, J., Koller, V., Payne, S., Hardie, A., \& Rayson, P. (2015) The online use of Violence and Journey metaphors by patients with cancer, as compared with health professionals: a mixed methods study. BMJ Supportive and Palliative Care.

Shokr Abdulmoneim, M. (2006): The Metaphorical Concept "Life is a Journey" in the Qur'an: a Cognitivesemantic Analysis. metaphorik.de. 10/2006, 94-132. 
Stojan, N. \& Mijić, S. N. (2019). Conceptual Metaphors in Political Discourse in Croatian, American and Italian Newspapers. Academic Journal of Interdisciplinary Studies, 8(1). Doi: 10.2478/ajis-20190007

Suhadi, J. (2011). Metaphor as a Stylistic Device of Islamic Teaching. MIQOT: Jurnal Ilmu-ilmu Keislaman, 35(1), 187-202.

Van Mulken, M., Van Hooft, A., \& Nederstigt, U. (2014) Finding the Tipping Point: Visual Metaphor and Conceptual Complexity in Advertising. Journal of Advertising, 43(4), 333-343. DOI: $10.1080 / 00913367.2014 .920283$

Velasco Sacristan, M.S. (2005). 'A Critical Cognitive-Pragmatic Approach to Advertising Gender Metaphors'. Intercultural Pragmatics, 2(3), 219-52.

Williams, G. (2001). Mediating between lexis and texts: Collocational networks in specialised corpora. Asp, la revue du GERAS, 31, 63-76. 